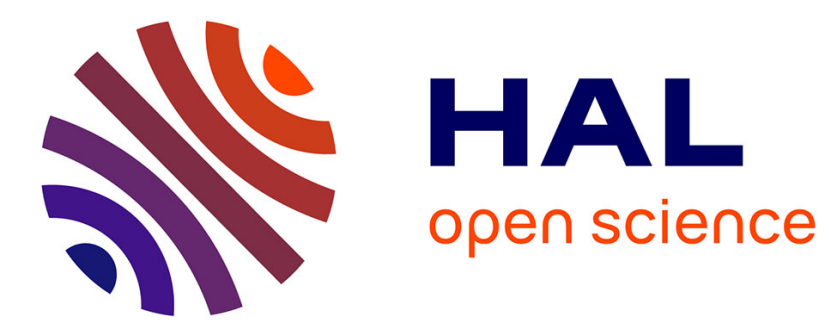

\title{
The Difficulty of Making Reparations Affects the Intensity of Collective Guilt
}

Michael T. Schmitt, Daniel A. Miller, Nyla R. Branscombe, Jack W. Brehm

\section{To cite this version:}

Michael T. Schmitt, Daniel A. Miller, Nyla R. Branscombe, Jack W. Brehm. The Difficulty of Making Reparations Affects the Intensity of Collective Guilt. Group Processes and Intergroup Relations, 2008, 11 (3), pp.267-279. 10.1177/1368430208090642 . hal-00571687

\section{HAL Id: hal-00571687 https://hal.science/hal-00571687}

Submitted on 1 Mar 2011

HAL is a multi-disciplinary open access archive for the deposit and dissemination of scientific research documents, whether they are published or not. The documents may come from teaching and research institutions in France or abroad, or from public or private research centers.
L'archive ouverte pluridisciplinaire HAL, est destinée au dépôt et à la diffusion de documents scientifiques de niveau recherche, publiés ou non, émanant des établissements d'enseignement et de recherche français ou étrangers, des laboratoires publics ou privés. 


\title{
The Difficulty of Making Reparations Affects the Intensity of Collective Guilt
}

\author{
Michael T. Schmitt \\ Simon Fraser University \\ Daniel A. Miller \\ Indiana University - Purdue University
}

Nyla R. Branscombe and Jack W. Brehm

University of Kansas

\begin{abstract}
We examined how the difficulty of making reparations for the harm done to another group affects the intensity of collective guilt. Men were confronted with information documenting male privilege and were told that they would have a chance to help women and reduce patriarchy by collecting signatures on a petition. We manipulated the difficulty of making reparations by asking participants to collect 5, 50, or 100 signatures. As predicted by Brehm's (1999) theory of emotional intensity, collective guilt was a non-monotonic function of the difficulty of making reparations. Men in the moderate difficulty (50 signatures) condition expressed greater collective guilt than participants in the low (5) or high (100) difficulty conditions. Results are discussed in terms of the implications for the theory of emotional intensity, collective guilt, and collective emotions more generally.
\end{abstract}

KEYWORDS collective guilt, emotion, emotional intensity, guilt, intergroup emotion

WHEN our ingroup commits unjust acts of harm against another group, we can experience collective guilt (for a review see Branscombe \& Doosje, 2004). Research suggests that collective guilt has a motivational quality. The more that people feel collective guilt, the more they support reparations for the harm done to the outgroup (Branscombe, Slugoski, \& Kappen, 2004; Iyer, Leach, \& Pedersen, 2004; Swim \& Miller, 1999) and reject ideologies that reinforce an exploitative relationship with the outgroup (Powell, Branscombe, \& Schmitt, 2005). Using Brehm's (1999) theory of emotional intensity, we predict that the perceived difficulty of making reparations influences the intensity with which collective guilt is felt in a non-monotonic fashion. Assuming that collective guilt represents the

\footnotetext{
Author's note

Address correspondence to Michael T.

Schmitt, Department of Psychology,

Simon Fraser University, Department of

Psychology, 8888 University Drive,

Burnaby, BC, Canada V5A 1S6

[email: mschmitt@sfu.ca]
} 
motivation to restore a just relationship with a harmed outgroup, we argue that the intensity of that motivational state will increase to match the difficulty of achieving reparations. When reparations appear easy to achieve, collective guilt should be relatively low. As the difficulty of reparations increases, the intensity of guilt should increase as well, because more motivation is required to make reparations. At some point, however, the difficulty of achieving reparations will exceed the importance of achieving them, and increased difficulty will lead to a decrease in guilt.

\section{What is collective guilt?}

How is it that people can feel guilt on behalf of their ingroup, even when they do not perceive themselves as personally responsible for the ingroup's harmful actions? According to selfcategorization theory (Turner, Hogg, Oakes, Reicher, \& Wetherell, 1987), the self can be experienced at different levels of inclusiveness. When people categorize themselves as individuals, they tend to focus on their unique qualities that differentiate them from other individuals. In contrast, when people self-categorize in terms of a social category, they tend to depersonalize the self and view themselves as more similar to other ingroup members. Accordingly, the ingroup's successes, failures, and wrongdoings are 'shared' by individual group members as representatives of a common category membership. By defining the self at a more inclusive level, the group and its relationships to outgroups acquire emotional significance (Smith, 1993).

Through depersonalization, people who self-categorize as members of a group that is responsible for illegitimate harm to another group will feel 'guilt by association', even in the absence of a sense of personal responsibility (Branscombe, Doosje, \& McGarty, 2002). Among high-status groups, the appraisal of the ingroup's advantage as illegitimate correlates with feelings of guilt (Montada \& Schneider, 1989; Schmitt, Behner, Montada, Muller, \& Muller-Fohrbrodt, 2000). Experimental evidence suggests that the experience of collective guilt is more likely when justifications for the ingroup's high-status are undermined, compared to when those justifications are reinforced (Miron, Branscombe, \& Schmitt, 2006). Similarly, when the ingroup is implicated in an unjust intergroup relationship, people feel more guilt compared to when attention is focused solely on the outgroup's plight (Powell et al., 2005).

In order for a person to experience feelings of collective guilt they must be willing to accept responsibility for the ingroup actions, even if they themselves had no part in the event. To the extent that people deny any form of collective responsibility and claim that only the individuals who perpetrated the harm directly can be assigned responsibility, then the experience of collective guilt is likely to be minimal. Branscombe et al. (2004) refer to the belief that groups can be held accountable for the actions of its members as 'whole group accountability', and find that agreement with this belief is positively correlated with the extent to which people report feeling collective guilt. Thus, one way for people to avoid the negative feeling of collective guilt is to take an ideological position that rejects the idea that whole groups can be assigned blame for the actions of some of their members.

Thus, collective guilt arises when people accept the notion of group accountability and they see the ingroup as responsible for perpetrating injustice against another group. In turn, collective guilt functions to urge reparations-meaning the creation or restoration of a just relationship with the harmed outgroup (Schmitt, Branscombe, \& Brehm, 2004). Reparations can include behaviors aimed at making up for past injustices committed by the ingroup, and behaviors aimed at creating a new intergroup relationship that eliminates current injustices. Research on guilt resulting from the ingroup's actions suggests that collective guilt does have these motivational characteristics. Dutch students who experienced guilt about their country's exploitation of Indonesia were more likely than those who did not feel guilty to support financial compensation to the Indonesian government (Doosje, Branscombe, Spears, \& Manstead, 1998). Guilt induced by perceptions of racial inequality motivates European Americans to reject racist ideologies 
(Powell et al., 2005) and support compensatory affirmative action policies (Branscombe et al., 2004; Iyer et al., 2004; Swim \& Miller, 1999). Similarly, guilt resulting from an individual's wrongdoings (when acting alone, not as a group member) appears to motivate people to repair the harm done (Baumeister, Stillwell, \& Heatherton, 1994; Frijda, 1986), apologize, and accept punishment (Roseman, Wiest, \& Swartz, 1994).

\section{Brehm's theory of emotional intensity}

To explore the implications of collective guilt's motivational character we relied on Brehm's (1999) theory of emotional intensity. Like other theories of emotion (Arnold, 1969; Duffy, 1941; Frijda, 1986; Lazurus, 1991), this theory of emotional intensity begins with the assumption that emotions are states of motivational arousal-they 'urge behavior designed to promote or prevent important outcomes or urge adaptation to important outcomes that have already occurred' (Brehm, 1999, p. 4). Emotions can be 'defined by an intentional structure: that of maintaining or changing a given situation' (Frijda, 1986, p. 98). That is, they are motivational states that organize and control behavior (e.g. Brehm \& Brummett, 1998). All emotions are assumed to have motivational properties, even if the function of the emotion is to discourage action, or if the function is not particularly clear (Brehm, 1999).

Emotions control behavior by organizing events in the environment in terms of their subjective importance at the time, and by maintaining behaviors necessary for coping with the most important event at a given moment. As argued by Levenson (1994, p. 123),

Emotions are short-lived psychological-physiological phenomena that represent efficient modes of adaptation to changing environmental demands. Psychologically, emotions alter attention, shift certain behaviors upward in response hierarchies, and activate relevant associative networks in memory. Physiologically, emotions rapidly organize the responses of disparate biological systems including facial expression, somatic muscular tonus, voice tone, autonomic nervous system activity, and endocrine activity to produce a bodily milieu that is optimal for effective response. Emotions serve to establish our position vis-a-vis our environment, pulling us toward certain people, objects, actions and ideas, and pushing us away from others'.

One way for a person to respond to an important event is to increase the intensity of the emotion aroused in response to that event (Brehm, 1999; Silvia \& Brehm, 2001). Thus, the emotion focuses attention on the event, and directs resources toward achievement of the function of that emotion (e.g. reparations in the case of guilt) while ignoring other signals. The more important the event, the greater the potential intensity. Generalizing from previous work on motivational arousal (Brehm \& Self, 1989), the theory of emotional intensity assumes that the intensity of a given emotion is a nonmonotonic function of the perceived magnitude of deterrence to attaining the function of the emotion. A deterrent is 'any factor that resists or opposes the function of the emotion' (Brehm, 1999, p. 5). Such factors include those that deter feeling the emotion, and those that deter behaviors urged by the emotion. The first class of factors can be thought of as reasons for not feeling the emotion, or reasons for feeling a different emotion. For example, reasons to feel happy can act as deterrents to sadness, and vice versa. Less obviously, distraction and demands on attention can act as deterrents to emotional experience, as these draw attention away from factors that instigated the emotion and alert the organism to other aspects of the environment that might call for different emotional responses.

The second class of deterrents can be thought of as reasons for not engaging in behaviors urged by the emotion, such as the effort required to engage in the behavior. For example, in the case of collective guilt, the difficulty of making reparations could serve as a deterrent. This second class of factors-those dealing with reasons for not engaging in the behavior urged by the emotion-has not yet been examined in tests of Brehm's theory of emotional intensity. Research on motivational intensity (without regard to specific emotions) has relied on manipulations of task difficulty, but most tests of the emotion theory have operationalized 
deterrents as reasons for feeling a different emotion than the person is currently feeling. One unique contribution of the present study is that we operationalize deterrents in terms of the difficulty of completing a behavior that would fulfill the function of the emotion.

How do deterrents affect emotional intensity? Theoretically, the maximum potential intensity of an emotion is determined by the importance of attaining the function of that emotion. When the level of deterrence is unknown, emotional intensity should rise to this maximum level as set by the importance of achieving the function of the emotion. A high level of intensity prepares a person for as yet unknown deterrents to the emotion-reasons for not engaging in the behavior urged by the emotion. The level of deterrence is likely to be unknown in situations where a person might know that something can be done to achieve the function of the emotion, but they do not know what deterrents might arise or what their magnitudes might be. In an experimental context, the level of deterrence is assumed to be unknown in control conditions that provide no information about deterrents.

In the absence of deterrents, emotional intensity is a function of the importance of achieving the function of the emotion. When, however, deterrents are known, a different process occurs, and emotional intensity varies non-monotonically as a function of the level of deterrence. When the level of deterrence is perceived to be low, emotional intensity should also be low, because little motivation is required to achieve the function of the emotion. As the perceived magnitude of deterrence increases, so too will emotional intensity, up to the point set by the importance of attaining the function of the emotion. If the perceived level of deterrence increases beyond that point, emotional intensity should drop substantially.

A number of experiments have offered evidence supporting this approach to emotional intensity-even with emotions with less obvious motivational properties. For example, Miron, Parkinson, \& Brehm (2007) found that the intensity of happiness varied as a function of deterrents to happiness. Happy participants were presented with reasons for not feeling happy (increases in graduation requirements) that varied in magnitude. Participants presented with a minor reason for not feeling happy (a small increase in graduation requirements) felt less happy than participants who were not presented with any deterrents. A moderate reason for not feeling happy led to relatively greater happiness. At a higher level of deterrence (a large increase in graduation requirements), however, happiness dropped to a relatively low level of intensity. The resulting cubic pattern of emotional intensity has also been found in studies of sadness (Silvia \& Brehm, 2001), anger, and sympathy (for a review see Brehm, 1999).

In the case of collective guilt, an obvious deterrent is the difficulty of making reparations for the harm done. When reparations are perceived as fairly easy to achieve, the intensity of collective guilt should be relatively low. As perceived difficulty of making reparations increases, so too should the intensity of collective guilt, up to the point at which guilt reaches its maximal level set by the importance of making reparations. When the difficulty of reparations increases beyond this point, collective guilt should drop to a low level of intensity. One of the interesting implications of this theory is that emotional intensity will be lowest when reparations appear rather easy or very difficult. Conversely, the intensity of collective guilt should be highest when the difficulty of reparations is either moderate or unknown.

\section{Overview of the experiment}

We tested our hypotheses regarding the effect of difficulty of reparations by examining men's experiences of collective guilt in response to their collective advantages relative to women. Inequality favoring men over women exists to some degree in essentially all contemporary societies (Abel \& Nelson, 1990; Keegen, 1993; Peterson \& Runyan, 1993; Wood \& Eagly, 2002). Women are disadvantaged in the labor force compared to men (Bartol, 1999; Reskin \& Padavic, 1994), are more likely than men to be poor (McLanahan \& Kelly, 1999), and are the primary victims of sexual assault (Rozee \& Koss, 2001). Although the form and extent of male privilege varies depending on social class, 
ethnicity, age, and sexual orientation (Connell, 1987), gender inequality clearly benefits men as a group at the expense of women as a group.

To invoke collective guilt, we presented men with detailed information regarding the ways in which gender inequality benefits their group and harms women (see Miron et al., 2006, for the use of a similar manipulation to invoke collective guilt in men). We then told them that we would give them an opportunity to reduce gender inequality by collecting signatures on a petition. To manipulate the difficulty of making reparations, we told participants that they would need to collect 5, 50, or 100 signatures (a control condition did not mention the petition). After participants learned about the petition, we measured collective guilt. We predicted that the intensity of collective guilt felt by men would be influenced by the difficulty of reparations as postulated by the theory of emotional intensity (Brehm, 1999). More specifically, we expected that when the difficulty of making reparations is low (5 signatures), guilt should also be low as compared to the control condition because little motivation should be required to complete the inequality-reducing behavior. However, when difficulty increases to a moderate level (50 signatures), we predicted that guilt should also increase compared to the low difficulty condition, because more effort would be required to carry out reparations. As difficulty further increases (100 signatures), we predicted that the intensity of guilt should decrease as compared to the moderate condition, because the difficulty of making reparations in this condition would outweigh the importance of doing so.

\section{Method}

\section{Participants and procedure}

Eighty men participated in partial fulfillment of a research requirement for an introductory psychology course. Participants were randomly assigned to one of four conditions: low, moderate, and high reparations difficulty, or a noinformation control condition.

In order to test our hypotheses, we had to be confident that participants would feel guilt, and thus be motivated to support reparations.
If participants on the whole did not experience guilt in any of the conditions, or were opposed to making reparations, then we would not expect deterrents to guilt to influence its intensity. Therefore, as described below, we created a context in which participants overall would experience guilt and be supportive of making reparations, at least at low and moderate levels of difficulty.

Furthermore, because the level at which the difficulty of making reparations will outweigh the importance of reparations needed to be determined a priori, we conducted a pretest to establish the levels of difficulty to use in our experiment. Men from the same population as our participants were asked the maximum number of signatures they would be willing to collect for the described petition. Because the average maximum was close to 50 , we chose that level for the moderate difficulty condition, and then chose numbers well above and below that for the high and low difficulty conditions respectively.

All participants read an essay that made them aware of the disadvantages suffered by women in the USA (following Schmitt, Branscombe, \& Postmes, 2003). Among other things, the essay described the gender wage gap, gender stereotypes about women's lack of competence, and the frequency of sexual assault against women. In part, the essay read 'Equal pay has been the law since 1963, however, women are still paid less than men-even when they have similar educational backgrounds, skills and experience'. In addition, participants read that

Men rarely worry about sexual assault, but women frequently think about the possibility of sexual assault when they go out at night alone, when they walk from a building to their car in an isolated parking lot, or when stranded in a broken down car.

We included this form of privilege not because it represents the most pervasive difference in the treatment of men and women, but because previous research (Branscombe, 1998) found that college men report freedom from fear of sexual assault as a major privilege of being a man. Thus, much of the essay focused on how women often fear going out alone at night, but men rarely worry about sexual assault. 
We assumed that sexual assault would be a relatively difficult form of inequality for men to justify; consequently, including information about this particular form of disadvantage helped ensure that inequality between women and men would be seen as illegitimate, a necessary precondition for inducing collective guilt.

\section{Manipulation of reparation difficulty}

After reading the essay on gender inequality, participants in the three experimental conditions went on to read about an ostensible opportunity to reduce inequality between women and men at their university. Participants read about a student-sponsored petition supporting improved lighting at the university and a free accompaniment service to walk both women and men between buildings or between buildings and parking lots at night. Participants read that after completing the questionnaire, they would have an opportunity to take a copy of the petition and collect signatures. The collection of signatures was presented explicitly as an opportunity to help reduce women's disadvantages at the university. In order to manipulate the difficulty of making reparations, we varied the number of signatures the participants would be asked to collect before they could return the petition. Participants read that they would need to collect 5,50 , or 100 signatures in the low, moderate, and high difficulty conditions, respectively. Participants in the control condition read nothing about the petition, thus, the difficulty of making reparations in this condition was ambiguous. The dependent measures described below followed the manipulation of reparation difficulty. At no point in the study were participants asked directly to collect signatures; participants were only told they would be given an opportunity to do so after their participation in the study was complete. Participants were not asked to indicate their willingness, intent, or commitment to collect signatures.

\section{Collective guilt}

Collective guilt was measured in two ways. First, participants responded to four items adapted from Branscombe et al.'s (2004) measure of collective guilt acceptance using a 1 (strongly disagree) to 7 (strongly agree) scale: 'I feel guilty about men's harmful actions toward women', 'I feel guilty about the negative things other men have done to women', 'I can easily feel guilty for bad outcomes brought about by members of my gender group', and 'I feel guilty when I think about the unfair disadvantages women suffer'. Second, participants also responded to a measure of currently felt guilt by indicating the extent to which they felt guilty at the present time on a 1 (not at all) to 7 (very much) scale. We factor analyzed these five collective guilt items. The first two eigenvalues were 13.58 and 0.74 respectively. Furthermore, all five items loaded highly on the first factor, suggesting a clear single-factor solution. Thus, the five items were combined into a single measure of collective guilt $(\alpha=.88)$.

\section{Whole group accountability}

The extent to which participants were willing to accept collective responsibility for the actions or inactions of their group was accessed with five items (e.g. 'If a group harms members of another group, the whole group should feel guilty' and 'Whole groups, like individuals, ought to be held accountable for their actions'; $\alpha=.89$ ) adapted from Branscombe et al. (2004). These items were measured on a 7-point scale (strongly disagree, strongly agree). Because willingness to accept ingroup responsibility is a necessary condition for feeling collective guilt, we measured this variable to use as a covariate in analyses of the intensity of collective guilt feelings.

\section{Legitimacy of gender inequality}

Beliefs about the legitimacy of discrimination against women were assessed on a 7-point scale (strongly disagree, strongly agree) with two items (i.e. 'I find it perfectly legitimate to discriminate against women', 'Treating women negatively based on their gender is justifiable'). These two items were averaged to create a single index of legitimacy $(\alpha=.89)$. This measure was included to rule out alternative explanations for our predicted findings, by demonstrating that the perceived legitimacy of gender inequality was not affected by our manipulation of reparations difficulty. 


\section{Results}

\section{Preliminary analyses}

As intended, the men in this sample viewed gender inequality as low in legitimacy $(M=1.65$ on a $1-7$ scale). Thus, one of the necessary conditions was met for collective guilt to be experienced: men appraised their relationship with the outgroup as illegitimate. Perceptions of legitimacy did not differ by condition $(F(3,76)=.38 p=.77)$, and were not significantly related to collective guilt $(r=-.13, p=.24) .{ }^{1}$ We found that the whole group accountability measure was positively related to participants' reports of how guilty they felt $(r=0.47, p<.001)$. However, participants' reports of whole group accountability did not differ by condition $(F(3,75)=1.17, p=.33)$. Thus, to control for individual differences in whole group accountability, a known necessary condition for the experience of collective guilt, this effect was added as covariate in all additional analyses. Using this covariate increases statistical power for detecting an effect of the experimental manipulation by partialling out variance in collective guilt that is not related to experimental condition (Frigon \& Laurencelle, 1993).

\section{Effects of condition on collective guilt}

Assuming that the function of collective guilt is to urge members of dominant groups to create a more just relationship with the outgroup, we predicted that guilt would be low in intensity when the difficultly of reparations was low or high, and relatively more intense when the difficulty of reparations was unknown or at a relatively moderate level. In order to test these predictions we submitted the collective guilt index to the following cubic contrast: control condition (1), low difficulty condition $(-1)$, moderate difficulty condition (1), high difficulty condition $(-1)$. The predicted contrast was significant $(F(1,74)=6.79$, $p=.01$ ), demonstrating that guilt was reliably higher in the control and moderate difficulty conditions than in the low and high difficulty conditions. ${ }^{2}$ As shown in Figure 1, guilt was lower in the low difficulty condition compared to the control condition $(t(37)=1.98, p=.025$, onetailed). In addition, guilt was higher in the moderate difficulty condition compared to both the low difficulty condition $(t(38)=-1.71$, $p=.046$, one-tailed) and high difficulty condition $(t(38)=-1.68, p=.048$, one tailed $)$. Thus, these results confirmed our hypotheses. ${ }^{3}$

\section{Discussion}

Supporting the theory of emotional intensity (Brehm, 1999), we found that the intensity of collective guilt was influenced in a non-monotonic fashion by the difficulty of reparations. The observed variation in the intensity of collective guilt

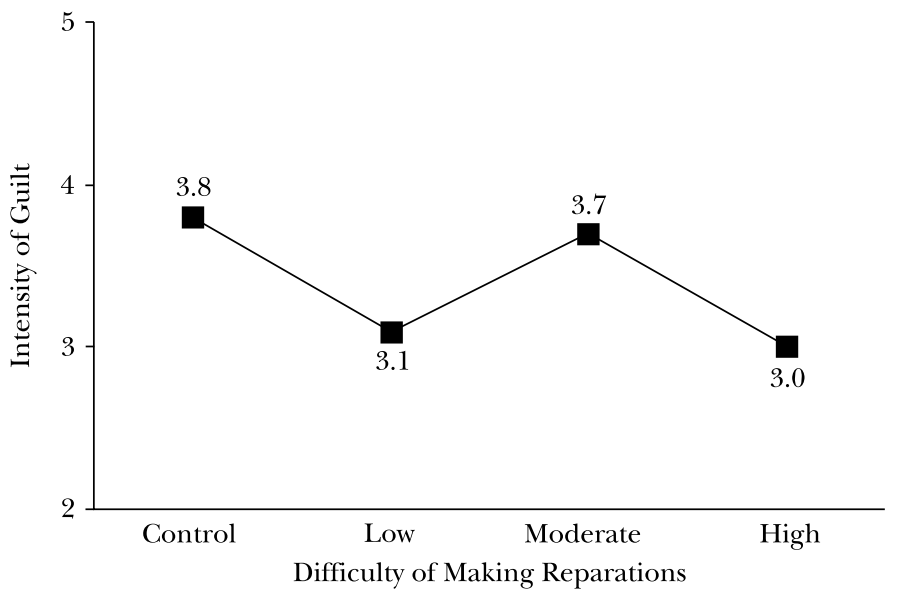

Figure 1. Men's experience of collective guilt as a function of the difficulty of making reparations for gender inequality. 
is consistent with predictions derived from the assumption that collective guilt is a motivational state, and a reflection of the differential levels of motivation required to enact reparations. This pattern of results is difficult to explain without assuming that collective guilt functions as a motivational state. For instance, one might suggest that the perceived difficulty of making reparations affected perceptions of the degree of injustice, and levels of guilt increased as the perceived degree of unjust harm increased. However, this notion would predict a continued linear increase in guilt as difficulty increased, and thus, cannot explain why guilt would be lower in the high difficulty condition relative to the moderate difficulty condition. Moreover, we measured perceptions of the illegitimacy of gender inequality and found that it did not reliably differ by condition.

Another alternative account of these findings might argue that participants' self-reported guilt represents dissonance reduction through effort justification-making one's reported emotion consistent with one's anticipated behavior. If participants plan to engage in reparation behavior in the low and moderate difficulty conditions (as we assume they would based on pretesting), guilt might be expected to be relatively high in the moderate difficulty condition, as more guilt would be consistent with the extra work required to complete reparations. In the high difficulty condition, assuming participants are not planning on engaging in reparations behavior, low guilt would be consistent with one's inaction. However, the cornerstone of a dissonance interpretation is commitment to one side or the other, in this case, to collect the signatures or not. Festinger's 1964 book made clear (as did Brehm \& Cohen, 1962) that commitment is a necessary condition for dissonance reduction processes to occur. Experiments reported in the 1964 book invariably demonstrated that there are no dissonance-like evaluation changes prior to commitment to one behavioral alternative or the other. As participants in the present study provided no clear commitment to engage (or not) in reparations behavior, dissonance theory cannot account for any changes in reported guilt.
Indeed, even the alternative account described above reads much like the emotional intensity interpretation, as the intensity of emotion precedes behavior, readying the individual for action or inaction. Moreover, other studies testing the theory of emotional intensity are immune to the effort-justification account (Miron et al., 2007; Silvia \& Brehm, 2001). In prior tests of the theory, participants are not presented with any particular behavioral option to fulfill the function of the instigated emotion. In those studies it seems implausible to assume that participants' responses were attempts to rationalize anticipated behavior.

\section{Implications for the study of emotional intensity}

This study offers support for the applicability of the theory of emotional intensity to a wide variety of emotions (Brehm, 1999). Past empirical support has come from studies of happiness, sadness, and anger. However, this study is the first to confirm that the predictions of emotional intensity theory also hold for guilt. Second, support for the theory of emotional intensity typically comes from studies finding that emotions with opposing valences can deter one another (e.g. reasons for feeling happy can deter sadness; Brehm, Brummet, \& Harvey, 1999). However, this is the first work to support the theory of emotional intensity by directly manipulating the difficulty of implementing an action tendency associated with a particular emotion. Third, these data are the first to test the theory of emotional intensity using an emotion based on a collective representation of self and not the personal self. Not only do these results further confirm the general applicability of the theory of emotional intensity, but they also confirm that collective emotions, like emotions more generally, have motivational properties. Thus, this research is consistent with the notion that emotions felt on behalf of an ingroup are just as 'real' as emotions tied to the individual self. Regardless of the level of self-definition (i.e. individual or group) involved in instigating the emotion, emotions seem to function similarly-as motivations urging and guiding behavior. 
One interesting implication of the theory of emotional intensity is that it predicts low levels of emotional arousal when deterrents are relatively low or relatively high. Despite resulting from different levels of deterrents, similar levels of emotional intensity represent similar levels of motivational arousal, and thus will result in similar levels of effort spent attempting to fulfill the function of the emotion. One difference between the low emotional intensity experienced under low and high deterrence is worth noting - a person experiencing low guilt because deterrents are low has potential for a greater intensity of guilt if new deterrents are encountered. In contrast, a person experiencing low guilt because deterrence requires a level of emotional intensity that surpasses its potential would continue to feel little guilt if additional deterrents are encountered.

Along the same lines, the theory predicts similar levels of high emotional intensity when deterrents are unknown, and when deterrence reaches the point at which additional deterrence would outweigh the importance of the function of the emotion. Future research could explore whether participants who are not presented with information about deterrence do feel a relative sense of uncertainty regarding aspects of the environment that might deter the function of the emotion. Such evidence would add additional support to the assumption that high emotional intensity when deterrence is operationalized as 'unknown' does arise from a sense of 'not knowing' what the level of deterrence will be.

\section{Implications for the study of collective guilt}

Deterrents to collective guilt are not limited to the difficulty of reparations. Other deterrents to collective guilt (i.e. reasons for not engaging in reparations) might include the costs that reparations incur in terms of the social identity of dominant group members. Establishing egalitarian intergroup relations is likely to result in real material costs (in terms of resources and power) to high-status groups, and reductions in the privileges and status that some groups hold over others are likely to result in costs to the social identities of high-status groups. Establishing intergroup equality is not just a matter of increasing the collective power and resources of disadvantaged groups, but also reducing (at least, in a relative sense) the collective power and resources of dominant groups. Social identity theory (Tajfel \& Turner, 1986) suggests that when a dominant group's social position is threatened, group members will be motivated to protect the group's collective interests. For example, Branscombe, Schmitt, and Schiffhauer (2007) found that highly identified White Americans expressed increased racism when forced to confront the advantages of their ethnic group membership, but that low identifiers expressed decreased racism, potentially reflecting increased collective guilt. Future research could investigate whether such threats to the social identity of dominant groups function as deterrents to collective guilt.

In addition, future work on collective guilt could fruitfully examine an assumption of the theory of emotional intensity that we have not fully explored-that the importance of achieving the function of an emotion determines its maximum intensity. When the goal of creating just relationships with harmed outgroups is relatively high in importance, the maximum potential intensity of collective guilt should be also high. Therefore, assigning importance to reparations as a goal increases the costs dominant group members are willing to incur before costs to the ingroup outweigh the importance of reparations. The present results suggest that a full understanding of collective guilt requires a consideration of factors that make just, fair relationships with lower status outgroups an important goal-one that can stand up against deterrents like the material and symbolic costs to the ingroup that would likely result from social change. Prior work suggests that perceived illegitimacy of the intergroup relationship is a predictor of collective guilt (Miron et al., 2007); perhaps the greater the moral transgressions of the ingroup, the more important it is to make reparations. In addition, Wohl, Branscombe, and Klar (2006) have argued that people feel greater collective guilt for harming groups with which they share a meaningful superordinate identity (e.g. nationality or humankind). By applying a similar standard of justice to both the ingroup 
and outgroup, a common superordinate category might increase the importance of reparations.

This perspective also leads us to consider general beliefs, ideologies and lay theories relevant to intergroup relations in terms of their implicit level of deterrence to collective guilt. Interestingly, the theory of emotional intensity suggests that belief systems which have opposite meanings can have similar implications for collective guilt. For instance, the theory suggests that collective guilt should be low if one's theory of intergroup relations suggests that establishing more egalitarian relations requires very little effort or cost, and if one's theory of intergroup relations suggests that egalitarian relations are impossible to achieve. Thus, the theory of emotional intensity may offer some insights into the ways in which apparently contradictory social beliefs can result in similar psychological (and political) ends. Political discourse regarding contemporary intergroup relations often contains implicit or explicit deterrents to collective guilt (e.g. 'We can't turn back the clock', 'If we apologize, they'll want financial reparations'; see Augoustinos \& LeCouteur, 2004). Reparations might be appraised as more difficult for a number of reasons, including a long period of time passing since the harm was done, or because the magnitude of harm is so great that justice requires reparations of a similar magnitude. More generally, a number of variables central to intergroup theorizing (e.g. the stability of intergroup status discrepancies, appraisals of ingroup strength, group identification) might be fruitfully conceptualized as deterrents to collective emotions.

The theory or emotional intensity also points to other deterrents to collective guilt that are irrelevant to the factors that give rise to collective guilt. Emotions reflect momentary adaptations to the environment, and thus must be responsive to new events that occur. Collective guilt could be deterred by any number of other events or situations and the emotions they give rise tohappiness resulting from seeing a good friend, frustration with a dead-end job, or sadness that occurs from watching depressing news reports.
With such a wide range of deterrents competing for the direction of emotional experience, will collective guilt ever make a difference? Whether these deterrents increase or decrease the intensity of guilt depends on the importance assigned to creating a just relationship with the outgroup. The greater the importance, the greater is the potential for guilt to rise in intensity in response to these other aspects of the environment.

Future research could expand on the present findings by including additional measures of collective guilt. People may be reluctant to report feeling guilt because it implicates their ingroup, and thus levels of reported guilt might underestimate the intensity of the experience. Perhaps this explains the moderate levels of guilt reported by our participants overall. More subtle, covert, or sensitive measures of guilt might better capture fluctuations in emotional intensity. In addition future research could measure the extent to which actual reparations behavior varies as a function of the perceived difficulty of making reparations. Measures of other emotions such as contempt, shame, or moral outgrage could determine whether people with a low level of guilt intensity are simply indifferent, or if they experience another emotion in place of guilt. This work could also be expanded to other intergroup contexts (e.g. race/ethnic relations) to test its generalizabilty. Assuming the conditions for the instigation of collective guilt are met, we see no reason why collective guilt would not respond similarly in other contexts.

In conclusion, the current research illustrates the empirical and theoretical benefits of considering the implications of collective guilt's motivational properties. We have demonstrated that the difficulty of making reparations acts as a deterrent to the experience of collective guilt, and affects the intensity of collective guilt in a non-monotonic fashion as predicted by the theory of emotional intensity (Brehm, 1999). We hope that these findings will motivate additional research that examines other possible deterrents to guilt so that we may better understand this social emotion. 


\section{Notes}

1. The lack of a significant correlation between legitimacy and guilt is somewhat surprising theoretically and in comparison to past research findings (Miron et al., 2006). However, there are two plausible reasons for not replicating this relationship. First, there was little variance in participants' responses to the legitimacy items, with participants using the extreme end of the scale to indicate that gender discrimination is illegitimate. Therefore, there was little variance to correlate with guilt. Second, the variability in guilt intensity in this study comes not from variability in legitimacy, but from the experimental manipulation of the difficulty of making reparations. The important point is although judgments of illegitimacy are a precondition for guilt, variation in illegitimacy judgments does not explain the variability in guilt in this particular sample.

2. The result of the cubic contrast for collective guilt without whole group accountability included as a covariate was similar $(F(1,76)=5.70, p=.02)$.

3. Participants also completed single item measures of anger, fear, and sadness. For each of these emotions, we examined the omnibus $F$ test and the cubic contrast. In no case were results significant, indicating that the effects we observed were specific to guilt.

\section{References}

Abel, E., \& Nelson, M. (1990). Circles of care: Work and identity in women's lives. Albany, NY: State University of New York Press.

Arnold, M. B. (1969). Human emotion and action. In T. Mischel (Ed.), Human action (pp. 167-197). New York: Academic Press.

Augoustinos, M., \& LeCouteur, A. (2004). On whether to apologize to Indigenous Australians: The denial of white guilt. In N. R. Branscombe \& B. Doosje (Eds.), Collective guilt: International perspectives (pp. 552-609). New York: Cambridge University Press.

Bartol, K. M. (1999). Gender influences on performance evaluations. In G. N. Powell (Ed.), Handbook of gender and work (pp. 165-178). London: Sage.

Baumeister, R. F., Stillwell, A. M., \& Heatherton, T. F. (1994). Guilt: An interpersonal approach. Psychological Bulletin, 115, 243-267.
Branscombe, N. R. (1998). Thinking about one's gender-group's privileges or disadvantages: Consequences for well-being in women and men. British Journal of Social Psychology, 37, 167-184.

Branscombe, N. R., \& Doosje, B. (Eds.). (2004). Collective guilt: International perspectives. New York: Cambridge University Press.

Branscombe, N. R., Doosje, B., \& McGarty, C. (2002). Antecedents and consequences of collective guilt. In D. M. Mackie \& E. R. Smith (Eds.), From prejudice to intergroup emotions: Differentiated reactions to social groups (pp. 49-66). Philadelphia: Psychology Press.

Branscombe, N. R., Schmitt, M. T., \& Schiffhauer, K. (2007). Racial attitudes in response to thoughts of white privilege. European Journal of Social Psychology, 37, 203-215.

Branscombe, N. R., Slugoski, B., \& Kappen, D. M. (2004). The measurement of collective guilt: What it is and what it is not. In N. R. Branscombe \& B. Doosje (Eds.), Collective guilt: International perspectives (pp. 16-34).

New York: Cambridge University Press.

Brehm, J. W. (1999). The intensity of emotion. Personality and Social Psychology Review, 3, 2-22.

Brehm, J. W., \& Brummett, B. H. (1998). The emotional control of behavior. In M. Kofta, G. Weary, \& G. Sedek (Eds.), Personal control in action (pp. 133-154). New York: Plenum.

Brehm, J. W., Brummett, B. H., \& Harvey, L. (1999). Paradoxical sadness. Motivation and Emotion, 23, 31-44.

Brehm, J. W., \& Cohen, A. R. (1962). Explorations in cognitive dissonance. New York: Wiley.

Brehm, J. W., \& Self, E. A. (1989). The intensity of motivation. In M. R. Rozenweig \& L. W. Porter (Eds.), Annual review of psychology (Vol. 40, pp. 109-131). Palo Alto, CA: Annual Reviews.

Connell, R. W. (1987). Gender and power: Society, the person and sexual politics. Stanford, CA: Stanford University Press.

Doosje, B., Branscombe, N. R., Spears, R., \& Manstead, A. S. R. (1998). Guilty by association: When one's group has a negative history. Journal of Personality and Social Psychology, 75, 872-886.

Duffy, E. (1941). An explanation of 'emotional' phenomena without the use of the concept 'emotion'. Journal of General Psychology, 25, 283-293.

Festinger, L. (1964). Conflict, decision, and dissonance. Stanford, CA: Stanford University Press. 
Frigon, J. Y., \& Laurencelle, L. (1993). Analysis of covariance: A proposed algorithm. Educational and Psychological Measurement, 53, 1-18.

Frijda, N. H. (1986). The emotions. Cambridge, UK: Cambridge University Press.

Iyer, A., Leach, C. W., \& Pedersen, A. (2004). Racial wrongs and restitutions: The role of guilt and other group-based emotions. In N. R. Branscombe \& B. Doosje (Eds.), Collective guilt: International perspectives (pp. 262-283). New York: Cambridge University Press.

Keegen, J. (1993). The history of warfare. New York: Knopf.

Lazurus, R. (1991). Emotion and adaptation. New York: McGraw-Hill.

Levenson, R. W. (1994). Human emotion: A functional view. In P. Ekman \& R. J. Davidson (Eds.), Fundamental questions about the nature of emotion (pp. 123-126). New York: Oxford University Press.

McLanahan, S. S., \& Kelly, E. L. (1999). The feminization of poverty: Past and future. In J. S. Chafetz (Ed.), Handbook of the sociology of gender (pp. 127-145). New York: Plenum.

Miron, A. M., Branscombe, N. R., \& Schmitt, M. T. (2006). Collective guilt as distress over illegitimate ingroup inequality. Group Processes $\mathcal{E}$ Intergroup Relations, 9, 163-180.

Miron, A. M., Parkinson, S. K., \& Brehm, J. W. (2007). Does happiness function like a motivational state? Cognition and Emotion, 21, 248-267.

Montada, L., \& Schneider, A. (1989). Justice and emotional reactions to the disadvantaged. Social Justice Research, 3, 313-344.

Peterson, V. S., \& Runyan, A. S. (1993). Global gender issues. Boulder, CO: Westview Press.

Powell, A. A., Branscombe, N. R., \& Schmitt, M. T. (2005). Inequality as ingroup privilege or outgroup disadvantage: The impact of group focus on collective guilt and interracial attitudes. Personality and Social Psychology Bulletin, 31, 508-521.

Reskin, B., \& Padavic, I. (1994). Women and men at work. Thousand Oaks, CA: Pine Forge Press.

Roseman, I. J., Wiest, C., \& Swartz, T. S. (1994). Phenomenology, behaviors, and goals differentiate discrete emotions. Journal of Personality and Social Psychology, 67, 206-221.

Rozee, P. D., \& Koss, M. P. (2001). Rape: A century of resistance. Psychology of Women Quarterly, 25, 295-311.
Schmitt, M., Behner, R., Montada, L., Muller, L., \& Muller-Fohrbrodt, G. (2000) Gender, ethnicity, and education as privileges: Exploring the generalizability of the existential guilt reaction. Social Justice Research, 13, 313-337.

Schmitt, M. T., Branscombe, N. R., \& Brehm, J. W. (2004). Gender inequality and the intensity of men's collective guilt. In N. R. Branscombe \& B. Doosje (Eds.), Collective guilt: International perspectives (pp. 75-92). New York: Cambridge University Press.

Schmitt, M. T., Branscombe, N. R., \& Postmes, T. (2003). Women's emotional responses to the pervasiveness of gender discrimination. European Journal of Social Psychology, 33, 297-312.

Silvia P. J., \& Brehm J. W. (2001). Exploring alternative deterrents to emotional intensity: Anticipated happiness, distraction, and sadness. Cognition and Emotion, 15, 575-592.

Smith, E. R. (1993). Social identity and social emotions: Toward new conceptualizations of prejudice. In D. M. Mackie \& D. L. Hamilton (Eds.), Affect, cognition, and stereotyping: Interactive processes in-group perception (pp. 297-315).

San Diego, CA: Academic Press.

Swim, J. K., \& Miller, D. L. (1999). White guilt: Its antecedents and consequences for attitudes toward affirmative action. Personality and Social Psychology Bulletin, 25, 500-514.

Tajfel, H., \& Turner, J. C. (1986). The social identity theory of intergroup behavior. In S. Worchel \& W. Austin (Eds.), The social psychology of intergroup relations (pp. 7-24), Chicago: Nelson-Hall.

Turner, J. C., Hogg, M. A., Oakes, P. J., Reicher, S. D., \& Wetherell, M. S. (1987). Rediscovering the social group: A self-categorization theory. Oxford, UK: Blackwell.

Wohl, M. J. A., Branscombe, N. R., \& Klar, Y. (2006). Collective guilt: Emotional reactions when one's group has done wrong or been wronged. European Review of Social Psychology, $17,1-37$.

Wood, W., \& Eagly, A. H. (2002). A cross-cultural analysis of the behavior of women and men: Implications for the origins of sex differences. Psychological Bulletin, 128, 699-727.

Paper received 2 November 2006; revised version accepted 8 October 2007. 


\section{Biographical notes}

MICHAEL T. SCHMitT received his PhD from the University of Kansas in 2002. While in graduate school, he was awarded a Fulbright Scholarship to study in the Netherlands. Michael is an assistant professor at Simon Fraser University, Burnaby, BC, Canada. His research examines collective identity and responses to social inequality.

DANIEL A. MILLER is an assistant professor of psychology at Indiana University-Purdue University, Fort Wayne. He received his $\mathrm{PhD}$ from Purdue University, in 2005. His research interests include intergroup emotions, collective action, and social cognition.

NYLA R. BRANSCOMBE received her PhD from Purdue University in 1986, and is professor of psychology at the University of Kansas. She co-edited the volume Collective Guilt: International Perspectives (2004, Cambridge University Press), which reports research concerning the antecedents and consequences of experiencing this group-level emotion, and Commemorating Brown: The Social Psychology of Racism and Discrimination (2008, American Psychological Association), which critically examines the role of psychological research in addressing oppression.

JACK W. BREHM received his PhD from the University of Minnesota in 1955, taught at Yale and Duke Universities before moving to the University of Kansas in 1975. He retired in 1996. $\mathrm{He}$ is author or co-author of articles and books on dissonance theory and reactance theory. 